\title{
FAPESP: POLÍTICA CIENTÍFICA
}

\author{
Por Eduardo Guimarães`
}

MOTOYAMA, Shoso. FAPESP: Uma

História de Política Científica e Tecnológica. São Paulo, Fapesp, 1999.

MOTOYAMA, Shoso e outros. Para uma História da FAPESP. Marcos Documentais. São Paulo, Fapesp, 1999.

Neste momento em que a questão da ciência vem tendo uma maior repercussão social, e que muito se tem discutido, tanto na mídia quanto no interior da comunidade científica, a importância da divulgação da ciência para maior conhecimento desta pela sociedade, uma obra que faz a história de uma instituição considerada modelar, não só no Brasil, é de extrema importância para a melhor discussão do lugar da política científica e da produção de conhecimento na nossa sociedade.

A obra interessa por dois aspectos globais: pela história da Fapesp, contada na sua relação com as condições em que se deram suas atividades; e pelo conjunto de informações documentais que traz, notadamente no segundo volume, destinado exclusivamente a isso.

A história que se conta no primeiro volume identifica um grande número de personagens deste relato: governantes, cientistas, deputados, diretores da Fapesp, do CNPq, da Capes, dirigentes de Associações científicas como a SBPC, a ABC, imprensa. E os vê no quadro de ações as mais diversas: a Segunda Grande Guerra, a Ditadura Vargas, o desenvolvimento brasileiro e suas relações internacionais, as instituições de pesquisa do Brasil (Institutos de Pesquisa, Universidades etc.).

\footnotetext{
* Professor Titular do Instituto de Estudos da Linguagem (IEL/Unicamp) e Coordenador do Núcleo de Desenvolvimento da Criatividade (Nudecri/Unicamp). Coordena atualmente, entre outros projetos, o Núcleo de Jornalismo Científico, financiado pelo Programa de Apoio a Núcleos de Excelência (Pronex/CNPq), que tem como objetivo, sobretudo, refletir sobre a produção e a circulação do conhecimento.
}

Rua, Campinas, 8: 171-175, 2002 
Fazendo um percurso linear de leitura vamos encontrar na Introdução, do organizador, uma apresentação geral da Fapesp, localizando-a nos cenários em que esteve envolvida desde sua concepção e fundação. Localiza o momento atual como um caracterizado pela pesquisa de ponta, o que exige que a Fundação se movimente de modo diferente e específico para enfrentar este novo modo de fazer ciência e tecnologia.

No Capítulo I, também do organizador, vamos encontrar o relato de toda a luta da comunidade científica de São Paulo, logo depois da Segunda Guerra e da Ditadura Vargas, para incluir na Constiutição Estadual um dispositivo que garantisse a existência de um organismo de fomento à pesquisa em São Paulo. Este dispositivo acabou sendo o conhecido artigo 123 da Constituição Paulista de 1947. Este artigo não só exigia a criação da instituição como destinava a ela $0,5 \%$ da receita do Estado. Tomando os eventos destes momentos, no cenário paulista, brasileiro e mundial, podem-se, segundo o autor, compreender as dificuldades para se chegar a este dispositivo constitucional e compreender por que em condições adversas, caracterizadas por uma mentalidade ligada à importação de produtos e de conhecimento, foi possível esta conquista. Para Motoyama, isto pode ser explicado pelo efeito de visibilidade que a ciência assumiu socialmente e para os governos a partir da constatação de que a ciência foi fundamental nos esforços de guerra, possibilitando a vitória dos aliados, com o custo da bomba atômica. Os esforços de guerra mostravam como era possível conseguir resultados tecnológicos em curto prazo, desde que fossem feitos investimentos adequados. Este cenário, mais a luta de cientistas brasileiros, dos Institutos de Pesquisa e das Universidades, cria um ambiente que torna possível a inclusão do artigo 123 na Constituição.

No Capítulo II, ainda do organizador da obra, vemos o percurso que vai da constituinte, em 47, até a criação da Fapesp. São 15 anos de lutas. A Fapesp é criada em 1960 e entra em funcionamento em 1962. Os acontecimentos narrados mostram como divisões, mesmo entre os cientistas, no modo de conceber o projeto, aliadas às dificuldades econômicas do Estado, vão postergando o cumprimento da obrigação constitucional. E isto está muito ligado também às posições populistas de governantes como Adhemar de Barros e Jânio Quadros. Está também ligado a posições, que se mantinham, que consideravam inútil a produção de conhecimento no Brasil. Neste período são criados o CNPq e a Capes, saídos, segundo o relato do autor, das mesmas condições do final da guerra. Estas instituições passam, nestes mesmos quinze anos, extremas dificuldades 
financeiras e de planejamento. Um ator fundamental nas lutas deste período foi a SBPC, que em nenhum momento deixou de defender a criação da Fapesp e uma mais adequada destinação de recursos federais e estaduais para a pesquisa. E estas dificuldades não são localizadas só nos organismos de fomento. Os Institutos de Pesquisa e as Universidades passam também por dificuldades semelhantes, devido aos baixos salários e à falta de uma carreira que indicasse uma progressão adequada para os pesquisadores. A criação da Fapesp se dá no período do governo de Carvalho Pinto, como parte de seu plano de ação (a instalação da Fapesp é a meta 9). Neste momento, mais uma vez, um fato científico momentoso joga a favor (o lançamento pela União Soviética do Sputnik). Alia-se a isso a presença no Governo de um político considerado pelos autores como da elite esclarecida do Estado. Todas as tratativas envolvem argumentações importantes de cientistas que mostram que $o$ investimento em pesquisa já ajudara São Paulo a resolver problemas importantes e que era hora de cumprir o mantato constitucional. Mais uma vez a SBPC atua claramente a favor da iniciativa. Assim, em 18 de outubro de 1960, pela lei 5.918, é instituída a Fundação de Amparo à Pesquisa do Estado de São Paulo. Deste estatuto já constava a obrigação de a
Fapesp usar no máximo 5\% de seu orçamento com gastos de custeio. Seu funcionamento efetivo precisou esperar ainda um pouco mais. Em 23 de maio de 1962 é aprovado o Estatuto da Fundação e em 31 de maio o Conselho Superior aprova seu regimento.

O Capítulo III é de autoria de Walkiria Costa Fuccilli Chassot e Amélia Império Hamburger. Ele nos relata o trajeto da Fundação desde o início de seu funcionamento em 1962 até 1969. São deste período as lutas e a resistência da Fapesp no período da ditadura militar. São deste período a interrupção do mandato do diretor científico, Alberto Carvalho da Silva, em virtude de sua cassação, pelo AI-5, e depois pelo impedimento de participar de qualquer organismo estatal, pelo AI-10. Neste período, a Fapesp consolida seu modo de funcionamento. Isto se caracteriza pelo rigor de sua organização jurídica, que evita brechas que possibilitassem ações contra sua autonomia e continuidade. Consolida-se também seu funcionamento de destinação de recursos centrado na diretoria científica. A Fapesp consolida-se assim como uma agência que atende a solicitações de auxílios e bolsas baseando-se em projetos que são julgados segundo sua qualidade e viabilidade. São também deste período as primeiras "iniciativas" da Fapesp, com as quais a 
Fundação procura um programa de indução de pesquisa que, de seu ponto de vista, são estratégicas para o desenvolvimento do Estado. Todo este esforço da Fundação é garantido pelo procedimento que ela instala, desde seus primeiros anos de funcionamento, de separar, no momento da concessão do auxílio, do montante necessário para atendê-lo integralmente. Isto deu à Fapesp um de seus predicados mais louvados, a continuidade do desembolso dos recursos segundo o planejado. Os esforços da Fapesp na formação de pessoal qualificado esbarra com freqüência na falta de uma política adequada de fixação de pesquisadores, em virtude, como sempre, dos baixos salários e da falta de uma carreira adequada, tanto nas universidades quanto nos Institutos de Pesquisa.

O Capítulo IV é de Francisco Assis de Queiroz e Lincoln Taira, e cobre o período que vai de 1969 a 1983 . Neste momento há uma luta específica: manter o que o artigo 123 da Constituição de 1947 estabelecera, possibilitando a criação da Fapesp. Isto é conseguido e o artigo 130 da Constituição Estadual de 1969 mantém as mesmas condições do artigo 123. Este período é de grandes dificuldades financeiras e é também o da luta para que o $0,5 \%$ destinado à Fundação, fosse a ela repassado em dia e no seu valor total. As irregularidades dos repasses ficaram mais graves em virtude da inflação que começa a crescer fortemente. A solução vem pela emenda constitucional 39 de 16 de dezembro de 1983, que obriga o repasse em duodécimos, mês a mês, e nos valores correntes. As dificuldades só não são maiores porque a FAPESP pode lançar mão de recursos próprios de seu patrimônio líquido. É assim que ela consegue neste período sustentar 1.280 bolsas, auxiliando fortemente na formação de mestres e doutores para São Paulo. Com isso a Fundação consolida seu modo de atuar e ajuda a constituir, segundo os autores, um etos do pesquisador-cientista. Este é um período de resistência, segundo os próprios autores: "Importou-nos aqui procurar mostrar como a comunidade científica e uma instituição encarregada de apoiar, financiar e fomentar a pesquisa, como é, em nosso caso, a Fapesp, elaboraram suas estratégias, poderíamos dizer, de sobrevivência, nesses períodos de instabilidade tanto política, quanto econômica e social." (p. 168)

No último capítulo, o quinto, de autoria de Marilda Nagamini, temos o relato da história da Fundação no período que vai da década de 1980 até hoje. É deste período a criação da figura do Coordenador de Área para auxiliar o trabalho do Diretor Científico. As atividades de fomento da Fapesp se mantêm e há um maior investimento nas chamadas iniciativas 
da Fapesp, através de seus programas especiais. Neste momento a Fundação traz uma novidade para os programas especiais, abrindo a possibilidade de que sejam também apresentados por interessados. Aqui está, no próprio dizer da autora, um embrião para os projetos temáticos que vão ter início em 1990, depois da constituição de 1989, que manteve o perfil jurídico da Fapesp e aumentou de $0,5 \%$ para $1 \%$ o total dos recursos da arrecadação para a Fundação. E aqui vemos cruzarem duas linhas de ação. De um lado a política da fundação que sempre procurou conseguir condições de desenvolver ações induzidas e favorecer ações conjuntas de cientistas. De outro a luta junto à constituinte federal e depois estadual para manter a possibilidade formal de existência da Fapesp, e aumentar sua dotação, diante da história de dificuldades que vinha tendo para atender a demanda crescente que se dava inclusive como resultado das ações da Fapesp na formação de maior número de pesquisadores. A criação dos projetos temáticos acabou por ser também uma passagem para novos projetos especiais, como é o caso do projeto Genoma. Isto é possibilitado pelo aumento de recursos da Fundação, por uma história recente de maiores experiências em pesquisas de grupo, e pela existência de uma rede de informática muito bem instalada (rede ANSP). Instalação que foi feita pela própria Fapesp, a qual também financiou a rede das Universidades e Institutos de Pesquisas através de um outro programa desta época, o programa de infraestrutura, ao lado do qual se desenvolveu o conhecido FAP-livros_. Este é, conforme a autora, um momento de ampliação das ações da Fapesp.

Quanto ao segundo volume da obra, não se pode deixar de registrar que ele traz documentos primários decisivos para a história da Fundação e para sua melhor compreensão. Entre estes destacam-se, além do conhecido artigo 123 da Constituição de 1947, textos de cientistas que fundamentaram a discussão para a criação da Fapesp, discursos de deputados estaduais em que se discutia a questão, documentos produzidos pela USP, decretos que instituem comissões para estudar a constituição da Fapesp, atas, projetos de lei, a lei que cria a Fapesp, o decreto aprovando os estatutos da Fundação, a emenda constitucional 39 , documentos de discussão no momento da constituinte de 1989, e outros.

A observação da história da Fundação de Amparo à Pesquisa do Estado de São Paulo, relatada nesta obra, nos mostra que a Fapesp passando por todos estes percursos e condições, revela como "do ponto de vista histórico, a ciência no país sempre esteve associada às necessidades tecnológicas ou 
políticas, para não dizer que nasceu exatamente dessas necessidades" (Motoyama V. I, p. 93). Ou seja, a história da Fapesp não é uma história vivida fora das condições sociais. A Fapesp não é um organismo de fomento à pesquisa pautado por procedimentos determinados exclusivamente por ações que se configuram estritamente no seu interior, ou estritamente no interior do domínio da ciência. O que a Fapesp soube muito bem fazer foi ser uma instituição que resultou de uma efetiva participação de um segmento da sociedade, os cientistas, não sendo simplesmente o resultado de uma ação do Estado ou de Governos. Ou seja, a Fapesp não tem sido, na sua história, um organismo co-optável pelo poder. 